\title{
Emergency Medicine Resident Physicians' Perceptions of Electronic Documentation and Workflow
}

\section{A mixed methods study}

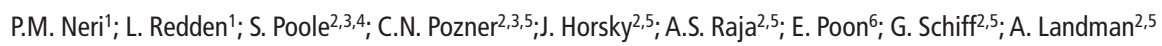 \\ ${ }^{1}$ Clinical \& Quality Analysis, Partners HealthCare System, Wellesley, MA; \\ ${ }^{2}$ Brigham and Women's Hospital, Boston, MA; \\ ${ }^{3}$ Neil and Elise Wallace STRATUS Center for Medical Simulation; \\ "Simulation Consulting, Phoenix, Arizona, USA; \\ ${ }^{5}$ Harvard Medical School, Boston, MA \\ ${ }^{6}$ Boston Medical Center, Boston University School of Medicine, Boston, MA
}

\section{Keywords \\ Workflow, electronic documentation, emergency department, electronic health records}

\section{Summary}

Objective: To understand emergency department (ED) physicians' use of electronic documentation in order to identify usability and workflow considerations for the design of future ED information system (EDIS) physician documentation modules.

Methods: We invited emergency medicine resident physicians to participate in a mixed methods study using task analysis and qualitative interviews. Participants completed a simulated, standardized patient encounter in a medical simulation center while documenting in the test environment of a currently used EDIS. We recorded the time on task, type and sequence of tasks performed by the participants (including tasks performed in parallel). We then conducted semi-structured interviews with each participant. We analyzed these qualitative data using the constant comparative method to generate themes.

Results: Eight resident physicians participated. The simulation session averaged 17 minutes and participants spent 11 minutes on average on tasks that included electronic documentation. Participants performed tasks in parallel, such as history taking and electronic documentation. Five of the 8 participants performed a similar workflow sequence during the first part of the session while the remaining three used different workflows. Three themes characterize electronic documentation: (1) physicians report that location and timing of documentation varies based on patient acuity and workload, (2) physicians report a need for features that support improved efficiency; and (3) physicians like viewing available patient data but struggle with integration of the EDIS with other information sources.

Conclusion: We confirmed that physicians spend much of their time on documentation $(65 \%)$ during an ED patient visit. Further, we found that resident physicians did not all use the same workflow and approach even when presented with an identical standardized patient scenario. Future EHR design should consider these varied workflows while trying to optimize efficiency, such as improving integration of clinical data. These findings should be tested quantitatively in a larger, representative study. 


\section{Correspondence to:}

Adam Landman, MD, MS, MIS, MHS

Department of Emergency Medicine

Brigham and Women's Hospital

75 Francis Street, Neville House

Boston, MA 02115

Email: ALANDMAN@partners.org
Appl Clin Inform 2015; 6: 27-41

http://dx.doi.org/10.4338/ACI-2014-08-RA-0065

received: September 2, 2014

accepted: December 15, 2014

published: January 21, 2015

Citation: Neri PM, Redden L, Poole S, Pozner CN, Horsky J, Raja AS, Poon E, Schiff G, Landman A. Emergency medicine resident physicians' perceptions of electronic documentation and workflow - a mixed methods study. Appl Clin Inf 2015; 6: 27-41

http://dx.doi.org/10.4338/ACI-2014-08-RA-0065 


\section{Background}

Electronic clinical documentation serves multiple purposes including communication, billing, maintenance of a legal record, and serves as a tool for synthesis and medical decision making. Electronic Health Record (EHR) incentive programs in the United States designed to stimulate health information technology (HIT) adoption require hospitals and providers to show they use the EHR "meaningfully" and meet certain objectives in order to receive incentive payments. The second stage of the meaningful use program recognizes the importance of electronic documentation by including it as a menu objective to fulfill program requirements [1]. In response to these policies and incentives, emergency departments (EDs) are increasingly adopting EHRs, but only $60 \%$ of US EDs have implemented electronic charting [2].

While electronic documentation systems have the potential to improve communication and medical decision-making, they can also take more time and contribute to workflow inefficiencies and thus can be barriers to adoption of HIT [3-8]. Efficiency and physician time are critical, particularly in EDs $[9,10]$. Emergency physicians often multi-task and frequently transition between activities quickly and unexpectedly while simultaneously handling multiple patients and frequent interruptions $[11,12]$. In addition, ED patient acuities and patient volumes vary, influencing the ways in which physicians perform routine tasks [13]. Time and motion studies have found that documentation and indirect patient care activities take a significant percentage of provider time [14, 15]. As we seek to optimize and gain more value from electronic documentation, Schiff and Bates suggest that we need to re-engineer documentation "with the goal of building a more distributed, reliable, and content-rich yet succinct and efficient system" [16]. Understanding the way ED physicians use electronic documentation is a first step in designing this next generation documentation system.

\section{Objectives}

Building on previous work that has identified the percentage of time spent on physician activities $[14,15]$, we sought to explore qualitatively how emergency physicians use electronic clinical documentation and also better understand their workflows and views on electronic documentation system features. We used a mixed methods approach combining task analysis in a simulated environment followed by a qualitative approach for understanding usability and work processes [17]. We hoped that the results would inform requirements for future systems and generate hypotheses for future study.

\section{Methods}

This was an exploratory mixed methods study performed in a medical simulation center using qualitative methods and task analysis in order to understand emergency physician electronic documentation use. This study was approved by the local institutional review board.

\subsection{Recruitment}

Resident physicians in our four-year emergency medicine (EM) residency program were invited to participate. All residents had training on the emergency department information system (EDIS) system and used the EDIS in clinical practice at an affiliated hospital. No additional formal training was included with the study. Further, residency didactic education included simulation sessions every two weeks, ensuring resident familiarity with the simulation center. We sent emails to all 60 EM resident physicians, with a goal of enrolling 10 participants, as a sample size of 5-10 has been previously determined to be appropriate for usability and task analyses [18-20]. We received a response from 17 residents and scheduled 10 to participate. We purposefully selected respondents to balance gender and training level based on schedule availability [21]. Residents were given a \$50 incentive 
payment for participating. Participation was voluntary and did not impact performance evaluations or employment; verbal consent was obtained from participants.

\subsection{Setting}

The study was performed at the Neil and Elise Wallace STRATUS Center for Medical Simulation at Brigham and Women's Hospital, which is used for interprofessional medical education and training, teamwork development, and clinical education and research. We worked with the simulation center experts to optimize the simulation environment for studying HIT in an ED setting [22, 23]. We configured the simulation center physical space to resemble a typical ED examination room and study staff was able to observe the session from an adjacent control room through a two way mirror. Resident physicians utilized a workstation on wheels (WOW) to access the electronic system and Morae usability software (TechSmith, Okemos, MI) was installed on the computer to aid in data collection. We also utilized recording equipment in the simulation center to capture audio and video of the sessions.

\subsection{Emergency Department Information System}

An EDIS is an EHR system designed specifically to manage data and workflow in support of ED patient care and operations [24]. The EDIS that we used in our study is used at an academic medical center ED ( $>$ Figure 1). It is an internally developed (Massachusetts General Hospital EDIS, Partners Healthcare, Boston, MA), web-based system with support for patient tracking and electronic clinical documentation. Users access the EDIS with one click from their workstation. The tracking board is presented geographically with rectangular tiles representing patients. Icons on the patient tiles allow users to quickly access components of the EDIS, including electronic documentation. These icons also enable access to separate internally developed order entry and results review systems, along with other enterprise clinical applications. A test environment of the EDIS was set-up with fictitious test patients for use during this study.

The EDIS physician documentation module allows a physician to document the entire encounter, including history of present illness, past medical history, social history, review of systems, physical exam, assessment and plan, test results, course, and disposition. It is designed with two types of functions to facilitate the insertion of textual information into the clinical note: the first retrieves selected clinical data from other clinical systems such as the problem list from the outpatient medical record or laboratory results; and, the second is a type of macro that allows for rapid insertion of templated text (e.g., neurological exam normal or no known allergies). The triage note which is accessible to the physician through the left navigation menu in the EDIS was pre-populated by study staff with appropriate chief complaint and vital sign information for the study patient scenario.

\subsection{Clinical Scenario}

We developed a clinical scenario representing a typical ED visit, a 55 year old male presenting with a headache after being hit in the head with a softball (Appendix A). An attending emergency physician (AL) played the standardized patient role for all eight sessions. He was moulaged to simulate a head injury and followed a standardized script to respond to the residents' history-taking and physical exam.

The resident physicians were briefed before the session began. During the briefings, they were instructed to document using the EDIS and a WOW as they normally would in the ED. Given that interruptions are common during ED care [11], the residents were interrupted when beginning to type into the assessment and plan section of the EDIS by a nurse actor who asked the residents to review an electrocardiogram for another patient. Residents were not required to complete the discharge instructions for the patient in the EDIS; however, they were asked to discuss the plan and disposition with the patient. The scenario ended either when the residents informed the research team that they had finished their documentation or if they exceeded the 20 minute time limit that we determined was sufficient for the encounter. 


\subsection{Data Collection}

The audio and video for each session was recorded. We also used the Morae software suite (TechSmith, Okemos, MI) designed to support usability studies to capture the participants' actions and keystrokes. Researchers in the control room used the Morae observer component to observe the users' interactions with the EDIS in real-time.

Two research team members collected data both during the simulated encounters and during review of the session videos, focusing on the task times and actions performed by the residents. Prior to the sessions, we identified major tasks that occur during an ED encounter, including activities that often occur in parallel, such as electronic documentation and history taking from patient. These predefined tasks included History Taking, Physical Examination, Patient Education Discussion, Documentation, Documentation and History Taking, History Taking and Physical Examination, Discussion with Patient and Documentation. These were pre-populated in Morae as coded markers that could be used with the Morae observer software to time-stamp tasks as they were occurring during the sessions. Observers recorded other behaviors as well, specifically as they relate to the use of the documentation system. Other behaviors included whether they documented inside or outside the exam room, how they responded to the interruption, whether they chose to order a head CT, how they used the buttons and macros, and other interactions with the system that we observed. Videos and Morae recordings were later reviewed by the research assistant and usability specialist (LR, PN) to clarify and validate data.

After the completion of the scenario and documentation, the participants were interviewed about their experience using the EDIS during the encounter in order to better understand their workflow and cognitive processes. One research team member $(\mathrm{PN})$ conducted one-on-one semi- structured interviews with the participants using a structured interview guide (Supplementary Appendix B) to understand their general experience with the EDIS and documentation during the scenario, their workflow, their information requirements and decision support needs, and specific EDIS interface elements and features. Participants were also asked to clarify specific behaviors they exhibited during the simulation sessions. Audio from the interviews was recorded and then professionally transcribed.

\subsection{Analysis}

Upon completion of the sessions, a research team member conducted a detailed review of the approximately 45 minute Morae and video recordings of each session to confirm time on each task, sequence of tasks, and actions taken by the residents. We report deidentified individual results as well as summary descriptive statistics. We calculated the time spent on the entire scenario and each predefined task as defined in section 3.5 above separately for each participant and also average times across participants. In addition, we identified and reported the sequence of tasks performed by each participant and the average length of time the participants spent on tasks that occurred in parallel and tasks involving documentation.

We analyzed the qualitative feedback from the interviews using the constant comparative method [25]. Transcripts from the interviews were reviewed together by three members of the research team (AL, LR, PN) and iteratively coded, after which the team identified and discussed each distinct statement or idea in order to come to consensus on a code. The codes were revised as the team read through each of the transcripts and a final coding scheme was developed. Finally, the researchers reviewed all the codes to identify themes related to the residents' experiences using the EDIS during an ED patient encounter and to select representative quotes for each theme. ATLAS.ti (ATLAS.ti Scientific Software Development GmbH, Berlin, Germany) software was used for qualitative data management.

\section{Results}

Of the 10 emergency medicine residents scheduled to participate, one served as our pilot participant but we were unable to capture audio and video of the session and therefore unable to include in this 
analysis. Another resident cancelled last minute and we were unable to reschedule or find a replacement. Eight emergency medicine residents ultimately participated and completed the study during March 2012. The participants included three senior residents (PGY 3-4) and five junior residents (PGY 1-2), most of whom reported average computer experience and self-guided computer training $(\triangleright$ Table 1).

\section{1 Task Analysis}

The entire simulation session including examination, history taking, documentation and discussion with the patient took an average of 16.7 minutes (range 8.3 to 23.5) ( $>$ Table 2). Tasks that included documentation (Documentation, Documentation and History Taking, and Discussion with patient and Documentation) comprised an average time of 11 minutes, which was $65 \%$ of the session. On average, 3.5 minutes (21\%) were spent on multiple tasks done in parallel.

The most common workflow sequence during the first part of the visit was electronic documentation and history-taking performed in parallel, and then physical examination, patient discussion regarding the plan, and finally additional electronic documentation. Five of the eight participants performed these major tasks in this order. The other three participants did not start with the parallel activity of documentation and history-taking, but rather focused on either documentation or history-taking as their first activity and their sequence varied for the remainder of the encounter. Most participants concluded the encounter by alternating between discussing the plan with the patient and actively documenting on the computer. The average number of transitions (switching between major tasks) was 6 ( $\triangleright$ Figure 2).

\section{2 Qualitative Results}

Three themes characterize emergency physician views on electronic clinical documentation, including (1) Physicians report that workflow varies in location and timing of documentation based on patient acuity and workload; (2) Physicians report a need for system features that support improved efficiency; and (3) Physicians like to view available patient data but they struggle with the integration of clinical data from disparate systems. ( Table 3).

\subsubsection{Variation in Location and Timing of Documentation}

Many participants described individual variation in the timing and location of documentation depending on certain factors such as the acuity of the patient case, the complexity of the patient, and the workload of the department.

"When you see patients a little bit slower or you're seeing patients that are more complex, they take a lot of medications, then I think sometimes documenting during evaluation is more possible and it works with work flow." (Participant 1, Senior Resident)

Participants shared their feelings on documenting outside the patient's room or inside the room with the patient; there was no clear consensus on a single approach. Participants expressed that they typically find many advantages to documenting during the encounter, such as improvements in efficiency and accuracy. Participants articulated that documenting while talking with the patient and conducting the exam ensures an efficient process. Others shared that doing the documentation at the point of care allows for more accurate and complete data capture.

"Because I find that especially in the evening when you're getting busy and you're seeing simultaneously a variety of different people, you get all that stuff mixed up, like who was allergic to morphine. If you can type it down as soon as they say it to you so that you don't forget. Rather than write on a piece of paper and then type it, that's just repeating, I'd rather just type it all in." (Participant 4, Junior Resident)

The participants who documented during the encounter explained how they sometimes use the documentation system to jot down notes and keywords that can later be used to jog their memories when they have time to complete the note. 
"The stuff that I want to get down right away while I'm in with the patient is their history. Sometimes it's not even full sentences, but key words that I want to be able to go to later whenever I'm finishing my note. Like the timing or like it's the left side of his head. Once I see a bunch of patients they can easily get scrambled up in my mind." (Participant 7, Senior Resident)

A number of the participants expressed concerns that documenting during the encounter could affect the doctor-patient relationship, such as this senior resident's comment: "I never feel quite as connected to the patient if I have the computer there." (Participant 7, Senior Resident)

\subsubsection{Features of Electronic Documentation Systems that Improve Efficiency}

Participants made a number of comments regarding enhancements to electronic clinical documentation systems that would improve efficiency and better support their workflow, such as the addition of drawing tools and better support for managing re-assessments, such as time stamps.

"When we do paper documentation we have a stick figure that we can draw on. If there was a single stick figure in these notes... then I could just make a circle for where there's a bruise - it would be nice." (Participant 1, Junior Resident)

"I guess my own frustration is at the reassessment, it'd be nice to put in my reassessment, and then press enter, and then automatically it says the time I put that in, and then gives me another option for another box to reassess it." (Participant 5, Junior Resident)

Participants also like the option of using buttons for inserting templated text such as normal exam findings.

"There is a template that you could click off certain aspects of the physical exam and then you just type in the rest, which is similar to written documentation where you can check off pre-printed boxes." (Participant 2, Senior Resident)

"I like for review of systems that it is really easy to click through the ones that are normal. Then the defaults for exam are streamlined." (Participant 7, Senior Resident)

\subsubsection{Integration with other Clinical Information Sources}

Many participants said that they like to review the outpatient record of the patient before seeing the patient if they have time. They tend to look for recent and pertinent information that might influence their decision making.

"As a senior resident, I'm not always the first one in the room. Whenever I send the medical student or more junior resident in [to see the patient first], I'll be looking at the [EHR] while they're in the room. Even if they haven't looked at it [EHR], I've framed the context in my mind for whatever they're gonna tell me" (Participant 7, Senior Resident)

"When I see someone roll in, and then I get a quick sense of where they're at from the medical standpoint, because a lot of times they either can't say - tell me - or they don't know themselves. That gives me a quick framework." (Participant 5, Junior Resident).

Some participants indicated they review other clinical sources differently depending on the patient's complaint and the complexity of the case:

"More in the complicated medical patients - even before I walk in a room I want to know their oncology history." (Participant 7, Senior Resident)

The majority of participants said they want to have vital signs taken during triage pre-populated into their progress note or have a way to easily import the vital signs from triage. The participants said that it can be difficult to view the triage note once they are in the middle of writing their note. 
"I feel like it's a separate step to look at the triage note, and in this case, what I should have done is I should have looked at the vitals before I actually saw the patient, just to get a sense of any abnormalities." (Participant 2, Senior Resident)

Most participants used buttons to retrieve selected clinical data from other systems, such as lab results or the problem list from the outpatient medical record. They find this helpful as a prompt for asking specific questions or items they missed during the encounter as well as a more efficient way to document.

"The pre-populated sections help prompt me for certain things, and then you can also add in other things" (Participant 2, Senior Resident)

While they find the ability to pull in data from other systems helpful, the participants expressed concern that importing data from other data sources may require some reconciliation to validate whether the data is accurate and up-to-date.

"I usually do [use buttons to automatically retrieve historical patient data from other systems], but it usually is just a long exhaustive list that's usually wrong. I usually do it just so I have a base and I'll just read it off to the patient... I'll go through each section and do the retrieve thing, and then try to go back and either add if there's something they tell me, or remove." (Participant 5, Junior Resident)

They also find that often they must re-format the imported data so it displays clearly in the ED documentation system.

"I want everything to be populated automatically in the results section, but normally when we use it [the retrieve buttons] populates a bunch of lines and then a lot of times it has these comments on results - the format which repopulates the labs is not intuitive. It requires a lot of editing and cutting out useless result comments." (Participant 3, Junior Resident)

\section{Discussion}

We conducted observations of resident physicians caring for a standardized patient in a medical simulation center and documenting the encounter in an EDIS. We examined tasks and documentation use during the encounter and interviewed participants about their preferences. Our finding that a large percent of time in an ED clinical encounter is spent on documentation activities (65\%) is similar to those of other studies in which documentation activities ranged from $23 \%$ to $59 \%$ of the encounter [7, 12, 14]. Our results also suggest a considerable amount of documentation is performed while the physician is performing another activity in parallel. We found that physicians transition back and forth between using the computer and performing other clinical encounter activities quite frequently and the specific workflow of each physician varied even on a standardized patient. We classified the qualitative feedback into three themes that characterize emergency physician clinical documentation:

1. Physicians report that workflow varies in location and timing of documentation based on patient acuity and workload;

2. Physicians reort a need for system features that support improved efficiency; and

3. Physicians like to view available patient data but they struggle with the integration of clinical data from disparate systems.

The task analysis findings, in addition to the qualitative interviews, highlight that there is not one single workflow or method that is used by all physicians or all situations. Recent research has shown that physicians vary considerably in their use of EHR features [26], and here we have shown that workflow varies as well. Rather than start the encounter documenting and history taking in parallel as many of the participants did, three of the participants started with documentation before entering the room with the patient or history taking. However, while variation in workflow and use of the 
system exist, there are still common requirements that we identified that can inform the design of systems to offer flexibility and support for the majority of the users, the majority of the time. Finding the balance between customizability and usability can be challenging, however. This raises the question of whether we can design a 'one size fits all' information system. Is there a point at which designers need to make the accommodations to support different workflows or situations by building separate systems or modules or is it possible to optimize one system and provide customizable options while still retaining usability and efficiency? While this remains an open question, this study suggests there is more opportunity for customization. Large, integrated EHR systems currently have modules for different areas of the hospital, such as the ED, operating room, and labor and delivery. This paradigm might be extended to user customized EHR configurations or situation customized EHRs, and could be useful for such extreme examples like a disaster EHR view, optimized for the rapid arrival of high acuity patients $[27,28]$.

The physicians in our study commonly reviewed clinical data in other systems and/or imported data into their note. Two of the resident physicians in our study reviewed data and began documenting as the first step in their workflow, before talking with the patient. The practice of reviewing data prior to seeing the patient has been called, "chart biopsy" [29] and raises many questions about what, how, and where such data is taken from and copied to. Secondly, ED physician notes often incorporate data from other areas of the EHR, such as the triage note, problem list, and laboratory results. In our EHR, these data are automatically imported into the ED physician note. Studies have cautioned against too much copy and paste data and standard text that masks the pertinent information $[30,31]$.

Another approach is to better understand and embrace these data sharing and integration workflows and then design the EHR to better support these workflows. For instance, a dashboard could be created to support the "chart biopsy," providing a single screen summarizing key clinical data for ED patients $[32,33]$. Further, pertinent clinical data could be made readily accessible while the physician is documenting. For example, the "Smart Forms" project provided a multi-panel view that attempted to provide this functionality, allowing concomitant views of the triage note and recent discharge notes [34-36]. Future systems could automatically and intelligently integrate information from disparate systems in anticipation of the needs of the physician [37]. Improved methods for managing common EHR elements, such as problem and medication lists, could help address the desire to incorporate these centralized EHR data into clinical documentation and the EHR without double entry, while ensuring data synchronization and reducing the possibility of data inconsistency. System design for integrating other clinical information must be done thoughtfully and take into consideration the presentation and accuracy of the data, as well as the quality of the resulting notes and displays. Our results support the value of conducting user research to identify data and workflow requirements of the physicians. Identifying requirements prior to development and implementation can offer opportunities for better integrating clinical data in the design of these systems.

\section{1 Limitations}

Our study had a number of limitations. We conducted the task analysis in a simulated environment that may not perfectly replicate ED conditions and workflow. Further, we were unable to include electronic order entry and results review in the simulations, deviating from usual physician workflow. Less time may have been spent on verbal order and results review during the scenarios, which may have increased the percent of time spent on documentation. However, the simulation approach allowed us to standardize the ED encounter and to make comparisons between participants, which would be difficult to do in clinical practice, given variation in patient presentations.

The scenario used represented a typical low acuity ED encounter. We understood from the resident interviews that more complex or highly urgent cases might have required a different workflow or different use of the system. The generalizabilty of our findings may also be limited since we conducted this study using a single EDIS at one site with only resident physicians. Our study had only eight participants, but this is considered adequate for identifying the majority of issues and patterns as supported by similar evaluations $[18,19]$. With the small sample size we were unable to identify systemic reasons for differences between the individual workflows of the participants. Larger sample 
sizes may be needed to test hypotheses raised by this study and to generalize findings to other systems, settings and clinicians.

\section{Conclusion}

Clinical documentation in the ED is a time-intensive task for physicians. The timing and location of clinical documentation may vary by physician. Improvements in the integration of disparate clinical systems and the availability of clinical information at the right time may be important if emergency physicians are to embrace and optimally use electronic clinical documentation. Further research on the work processes and information requirements of ED physicians is necessary to design systems that move away from our current solutions and better meet the needs of the physicians.

\section{Clinical Relevance}

Improved understanding of clinical tasks, workflows, and physician uses of EHR systems can allow for identification of areas for improvement in the design and usability of these systems in order to better address the needs of the physician. We found that physicians often perform electronic documentation in combination with other clinical tasks and that they may use distinct workflows even when approaching a standard patient. By understanding the inefficiencies and the missed opportunities for automation and integration, clinical documentation systems might be improved in order to better support physician work processes and increase efficiency.

\section{Conflict of Interest}

Drs. Horsky, Schiff and Raja, Ms. Neri, and Ms. Redden have no financial disclosures. Dr. Poon received funding from an AHRQ grant and lecture fees/honoraria from QuantiaMD and Beckton, Dickinson and Company. Dr. Landman received grant funding from the Brigham and Women's Hospital. Dr. Pozner provided expert testimony unrelated to this work. Mr. Poole is now principal of Simulation Consulting, a firm he started after the completion of this study but prior to manuscript preparation and publication.

\section{Human Subjects Protection}

The study was performed in compliance with the World Medical Association Declaration of Helsinki on Ethical Principles for Medical Research Involving Human Subjects, and was reviewed by the Partners HealthCare Institutional Review Board

\section{Acknowledgements}

The authors wish to thank the resident physicians who participated in the study, as well as Camille Ducharme and Andrew Reisner, MD, from the Massachusetts General Hospital for their support. This study was generously funded by the Brigham and Women's Hospital Department of Emergency Medicine Esther B. Kahn Fund. This work was presented as a poster at the American Medical Informatics Association Annual Symposium in Chicago, IL, in November 2012. 


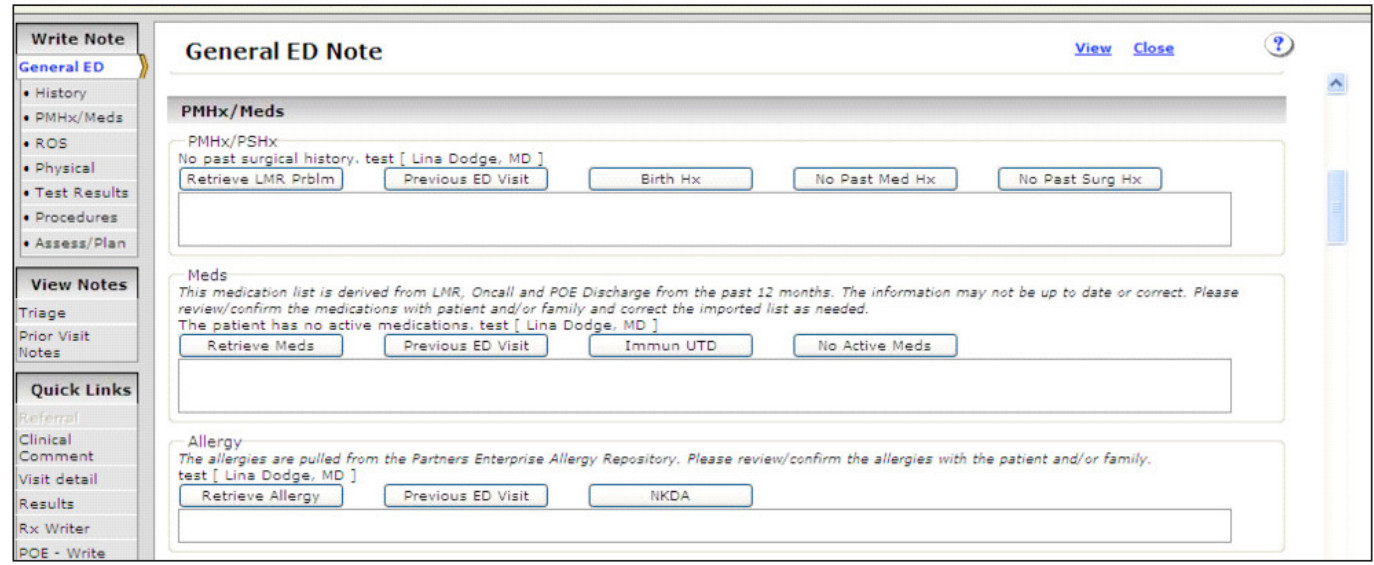

Fig. 1 Emergency Department Information System - Screenshot of General ED Note Section

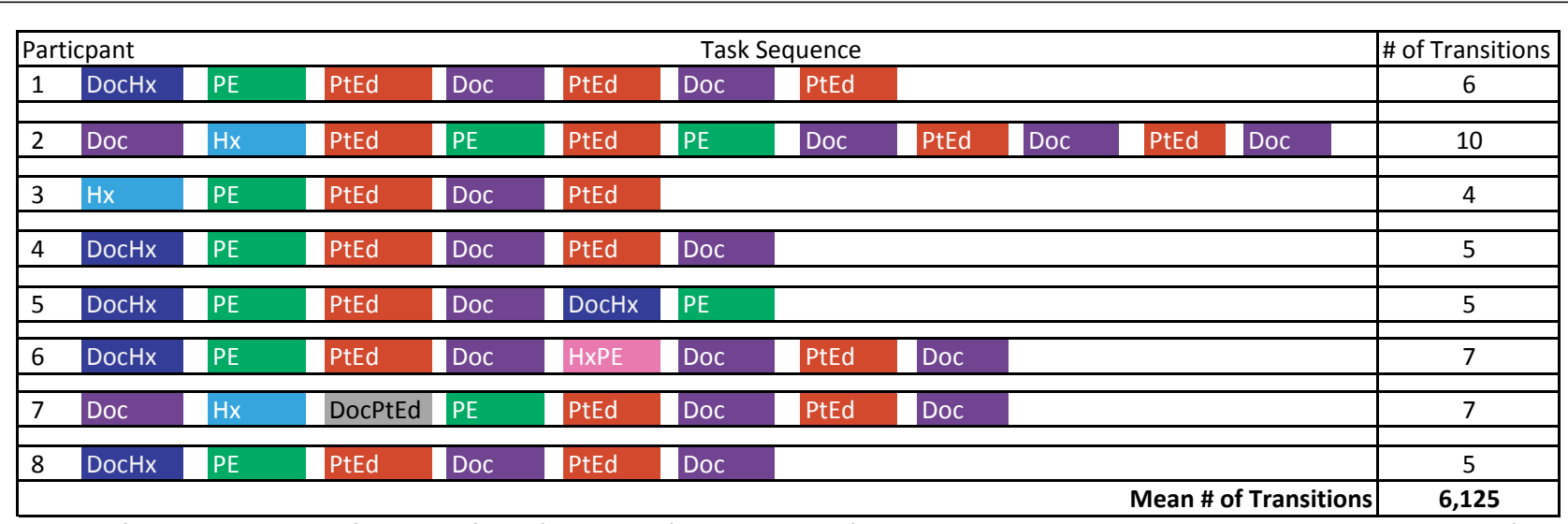

Task Key: Hx - History Taking; PE - Physical Exam; PtEd - Discussion with Patient; Doc - Documentation; DocHx - Documentation and History Taking; HxPE - History Taking and Physical Exam; DocPtEd - Discussion with Patient and Documentation

Fig. 2 Task Sequence by Participant 
Table 1 Characteristics of Participants

\begin{tabular}{|l|l|l|l|l|}
\hline Participant & Gender & Training Level & $\begin{array}{l}\text { Self Reported } \\
\text { Computer Experience }\end{array}$ & $\begin{array}{l}\text { Self Reported } \\
\text { Computer Training }\end{array}$ \\
\hline 1 & Male & Junior & expert & $\begin{array}{l}\text { self guided, } \\
\text { workshops/conferences }\end{array}$ \\
\hline $\mathbf{2}$ & Female & Senior & average & self guided \\
\hline 3 & Male & Junior & expert & computer science courses \\
\hline 4 & Female & Junior & average & $\begin{array}{l}\text { self guided, } \\
\text { computer science courses }\end{array}$ \\
\hline 5 & Female & Junior & average & self guided \\
\hline 6 & Male & Senior & average & self guided \\
\hline 7 & Female & Senior & average & self guided \\
\hline 8 & Male & Junior & average & self guided \\
\hline
\end{tabular}

Table 2 Time-on-task (in minutes)

\begin{tabular}{|c|c|c|c|c|c|c|c|c|c|c|}
\hline & \multicolumn{8}{|c|}{ Participant } & \multirow{2}{*}{$\begin{array}{l}\text { N partici- } \\
\text { pants } \\
\text { that per- } \\
\text { formed } \\
\text { task }\end{array}$} & \multirow{2}{*}{$\begin{array}{l}\text { Mean } \\
\text { Time } \\
\text { on } \\
\text { Task } \\
\text { (min) }\end{array}$} \\
\hline & 1 & 2 & 3 & 4 & 5 & 6 & 7 & 8 & & \\
\hline \multicolumn{11}{|l|}{ Singular Tasks } \\
\hline $\begin{array}{l}\text { History taking from } \\
\text { patient }\end{array}$ & & 2.5 & 1.8 & & & & 0.3 & & 3 & 1.5 \\
\hline Physical exam & 2.0 & 1.4 & 1.6 & 3.3 & 5.3 & 1.9 & 2.3 & 3.0 & 8 & 2.6 \\
\hline $\begin{array}{l}\text { Discussion with pa- } \\
\text { tient } \\
\text { (diagnosis, results, } \\
\text { plan) }\end{array}$ & 3.4 & 2.5 & 1.2 & 3.2 & 2.0 & 3.4 & 2.8 & 2.9 & 8 & 2.7 \\
\hline $\begin{array}{l}\text { Electronic documen- } \\
\text { tation }\end{array}$ & 6.2 & 10.8 & 3.7 & 5.3 & 4.6 & 8.5 & 7.7 & 12.2 & 8 & 7.4 \\
\hline \multicolumn{11}{|l|}{ Parallel Tasks } \\
\hline $\begin{array}{l}\text { History taking an } \\
\text { electronic documen- } \\
\text { tation }\end{array}$ & 3.5 & & & 4.3 & 5.7 & 4.9 & & 5.4 & 5 & 4.8 \\
\hline $\begin{array}{l}\text { History taking and } \\
\text { physical exam }\end{array}$ & & & & & & 0.8 & & & 1 & 0.8 \\
\hline $\begin{array}{l}\text { Discussion with pa- } \\
\text { tient and } \\
\text { electronic documen- } \\
\text { tation }\end{array}$ & & & & & & & 3.3 & & 1 & 3.3 \\
\hline $\begin{array}{l}\text { Total Time per Par- } \\
\text { ticipant }\end{array}$ & 15.2 & 17.1 & 8.3 & 16.0 & 17.6 & 19.5 & 16.4 & 23.5 & & 16.7 \\
\hline
\end{tabular}


Table 3 Themes that characterize Emergency Medicine Resident Physician Views and Use of Electronic Clinical Documentation

\begin{tabular}{|c|c|}
\hline Theme & Concepts \\
\hline $\begin{array}{l}\text { Variation in location } \\
\text { and timing of docu- } \\
\text { mentation }\end{array}$ & $\begin{array}{l}\text { Factors that influence location and timing of documentation include: } \\
\text { - Acuity of the patient case } \\
\text { - Complexity of the patient } \\
\text { - Workload of the department } \\
\text { Pros/cons of documenting during the patient encounter: } \\
\text { - Improvements in efficiency and accuracy } \\
\text { - Ability to insert prompts/keywords into real time documentation that help when com- } \\
\text { pleting note later } \\
\text { - Concerns that documenting during the encounter could affect the doctor-patient rela- } \\
\text { tionship }\end{array}$ \\
\hline $\begin{array}{l}\text { Features of clinical } \\
\text { documentation sys- } \\
\text { tems that improve } \\
\text { efficiency }\end{array}$ & $\begin{array}{l}\text { Suggestions for improving the efficiency of electronic documentation: } \\
\text { - Drawing tools } \\
\text { - Better support for managing re-assessments } \\
\text { - Templated text }\end{array}$ \\
\hline $\begin{array}{l}\text { Integration with other } \\
\text { clinical information } \\
\text { sources }\end{array}$ & $\begin{array}{l}\text { Review of additional sources of patient data: } \\
\text { - Review of the outpatient record before seeing the patient is often performed, if time } \\
\text { permits } \\
\text { - Review of clinical sources outside the ED information system depends on the patient's } \\
\text { complaint and the complexity of the case } \\
\text { Importing and accessing other data during documentation: } \\
\text { - Desire for triage vital signs to be pre-populated into physician documentation or be } \\
\text { easily imported } \\
\text { - Buttons to retrieve selected clinical data from other systems, such as lab results or the } \\
\text { problem list from the outpatient medical record were used by most participants } \\
\text { - Importing data from other data sources may require some reconciliation to validate } \\
\text { whether the data are accurate and up-to-date }\end{array}$ \\
\hline
\end{tabular}




\section{References}

1. Meaningful Use Stage 2 Overview Tipsheet. 2012; Available from: http://www.cms.gov/Regulations-andGuidance/Legislation/EHRIncentivePrograms/Downloads/Stage2Overview_Tipsheet.

2. Landman AB, Bernstein SL, Hsiao AL, Desai RA. Emergency Department Information System Adoption in the United States. Acad Emerg Med 2010; 17(5): 536-544. doi: 10.1111/j.1553-2712.2010.00722.x.

3. Kellermann AL, Jones SS. What it will take to achieve the as-yet-unfulfilled promises of health information technology. Health Aff (Millwood). 2013;32(1): 63-68. Epub 2013/01/09. doi: 10.1377/hlthaff.2012.0693. PubMed PMID: 23297272.

4. Middleton B, Bloomrosen M, Dente MA, Hashmat B, Koppel R, Overhage JM, Payne TH, Rosenbloom ST, Weaver C, Zhang J. Enhancing patient safety and quality of care by improving the usability of electronic health record systems: recommendations from AMIA. J Am Med Inform Assoc 2013 doi: 10.1136/amiajnl-2012-001458.

5. Poissant L, Pereira J, Tamblyn R, Kawasumi Y. The impact of electronic health records on time efficiency of physicians and nurses: a systematic review. J Am Med Inform Assoc 2005; 12(5): 505-516. Epub 2005/05/21. doi: 10.1197/jamia.M1700. PubMed PMID: 15905487; PubMed Central PMCID: PMCPmc1205599.

6. Ammenwerth E, Spotl HP. The time needed for clinical documentation versus direct patient care. A worksampling analysis of physicians' activities. Methods Inf Med 2009; 48(1): 84-91. Epub 2009/01/20. PubMed PMID: 19151888.

7. Kim CS, Lovejoy W, Paulsen M, Chang R, Flanders SA. Hospitalist time usage and cyclicality: opportunities to improve efficiency. J Hosp Med 2010; 5(6): 329-334. Epub 2010/08/31. doi: 10.1002/jhm.613. PubMed PMID: 20803670.

8. Oxentenko AS, West CP, Popkave C, Weinberger SE, Kolars JC. Time spent on clinical documentation: a survey of internal medicine residents and program directors. Arch Intern Med 2010; 170(4): 377-380. Epub 2010/02/24. doi: 10.1001/archinternmed.2009.534. PubMed PMID: 20177042.

9. Perry JJ, Sutherland J, Symington C, Dorland K, Mansour M, Stiell IG. Assessment of the impact on time to complete medical record using an electronic medical record versus a paper record on emergency department patients: a study. Emerg Med J 2013. Epub 2013/08/27. doi: 10.1136/emermed-2013-202479. PubMed PMID: 23975593.

10.Park SY, Lee SY, Chen Y. The effects of EMR deployment on doctors' work practices: A qualitative study in the emergency department of a teaching hospital. Int J Med Inform 2012; 81(3): 204-217. doi: 10.1016/j.ijmedinf.2011.12.001.

11. Chisholm CD, Collison EK, Nelson DR, Cordell WH. Emergency Department Workplace Interruptions Are Emergency Physicians "Interrupt-driven" and "Multitasking"? Acad Emerg Med.2000; 7(11): 1239-1243. doi: 10.1111/j.1553-2712.2000.tb00469.x.

12. Weigl M, Muller A, Zupanc A, Angerer P. Participant observation of time allocation, direct patient contact and simultaneous activities in hospital physicians. BMC health services research 2009; 9: 110. Epub 2009/07/01. doi: 10.1186/1472-6963-9-110. PubMed PMID: 19563625; PubMed Central PMCID: PMC2709110.

13. Chisholm CD, Weaver CS, Whenmouth L, Giles B. A task analysis of emergency physician activities in academic and community settings. Ann Emerg Med 2011; 58(2): 117-122. Epub 2011/02/01. doi: 10.1016/j.annemergmed.2010.11.026. PubMed PMID: 21276642.

14. Hockberger RS. The Model of the Clinical Practice of Emergency Medicine. Acad Emerg Med 2001; 8(6): 660-681. doi: 10.1111/j.1553-2712.2001.tb00182.x.

15.Schiff GD, Bates DW. Can electronic clinical documentation help prevent diagnostic errors? N Engl J Med 2010; 362(12): 1066-1069. Epub 2010/03/26. doi: 10.1056/NEJMp0911734. PubMed PMID: 20335582.

16. Overhage JM, Perkins S, Tierney WM, McDonald CJ. Controlled trial of direct physician order entry: effects on physicians' time utilization in ambulatory primary care internal medicine practices. J Am Med Inform Assoc 2001; 8(4): 361-371. Epub 2001/06/22. PubMed PMID: 11418543; PubMed Central PMCID: PMCPmc130081.

17.Sofaer S. Qualitative methods: what are they and why use them? Health Serv Res. 1999;34(5 Pt 2):1101-18. Epub 1999/12/11. PubMed PMID: 10591275; PubMed Central PMCID: PMCPmc1089055.

18. Nielsen J. Why you only need to test with 5 users Alertbox2000. Available from: http://www.useit.com/ alertbox/20000319.html

19. Virzi RA. Refining the test phase of usability evaluation: how many subjects is enough? Hum Factors 1992; 34(4): 457-468.

20. Faulkner L. Beyond the five-user assumption: Benefits of increased sample sizes in usability testing. Behavior Research Methods, Instruments, \& Computers 2003; 35(3): 379-383. 
21.Patton MQ. Qualitative Research \& Evaluation Methods. 3rd ed. Thousand Oaks, CA: SAGE Publications, Inc.; 2002.

22.Landman AB, Redden L, Neri P, Poole S, Horsky J, Raja AS, Pozner CN, Schiff G, Poon EG. Using a medical simulation center as an electronic health record usability laboratory. J Am Med Inform Assoc 2013. doi: 10.1136/amiajnl-2013-002233. PubMed PMID: 24249778.

23. Lawton K, Binzer K, Skjoet P, Jensen S. Lessons Learnt from Conducting a High Fidelity Simulation Test in Health IT. Patient Safety Informatics 2011; 166: 217-226.

24. Rothenhaus T, Kamens D, Keaton BF, Nathanson L, Nielson J, McClay JC, Taylor TB, Vallarin A. Emergency Department Information Systems: Primer for Emergency Physicians, Nurses, and IT Professionals. American College of Emergency Physicians: Resolution 22(07) Task Force White Paper. 2009. Available from: http://apps.acep.org/WorkArea/DownloadAsset.aspx?id=45756

25. Glaser B, Strauss A. The Discovery of Grounded Theory: Strategies for Qualitative Research. Chicago, IL: Aldine Transaction; 1967.

26. Ancker JS, Kern LM, Edwards A, Nosal S, Stein DM, Hauser D, Kaushal R. How is the electronic health record being used? Use of EHR data to assess physician-level variability in technology use. J Am Med Inform Assoc 2014. doi: 10.1136/amiajnl-2013-002627.

27.Diana A. Marathon Bombing Lessons: Boston Hospital Revamps Information Systems - InformationWeek. InformationWeek [Internet]. 2014. Available from: http://www.informationweek.com/healthcare/ clinical-information-systems/marathon-bombing-lessons-boston-hospital-revamps-informationsystems/d/d-id/1234846.

28. Landman A, Teich JM, Pruitt P, Moore SE, Theriault J, Dorisca E, Harris S, Crim H, Lurie N, Goralnick E. The Boston Marathon Bombings Mass Casualty Incident: One Emergency Department's Information Systems Challenges and Opportunities. Ann Emerg Med. 2014. Epub 2014/07/07. doi: 10.1016/j.annemergmed.2014.06.009. PubMed PMID: 24997562.

29. Hilligoss B, Zheng K. Chart biopsy: an emerging medical practice enabled by electronic health records and its impacts on emergency department-inpatient admission handoffs. J Am Med Inform Assoc 2013; 20(2): 260-267. Epub 2012/09/11. doi: 10.1136/amiajnl-2012-001065. PubMed PMID: 22962194; PubMed Central PMCID: PMCPmc3638186.

30. Weir CR, Hurdle JF, Felgar MA, Hoffman JM, Roth B, Nebeker JR. Direct text entry in electronic progress notes. An evaluation of input errors. Methods Inf Med 2003; 42(1): 61-67. Epub 2003/04/16. doi: 10.1267/meth03010061. PubMed PMID: 12695797.

31. O’Donnell HC, Kaushal R, Barron Y, Callahan MA, Adelman RD, Siegler EL. Physicians' Attitudes Towards Copy and Pasting in Electronic Note Writing. J Gen Intern Med 2009; 24(1): 63-68. doi: 10.1007/s11606-008-0843-2. PubMed PMID: 18998191; PubMed Central PMCID: PMC2607489.

32.Zalis M, Harris M. Advanced search of the electronic medical record: augmenting safety and efficiency in radiology. J Am Coll Radiol 2010; 7(8): 625-633. Epub 2010/08/04. doi: 10.1016/j.jacr.2010.03.011. PubMed PMID: 20678732.

33. QPID ${ }^{\mathrm{m}}$ | Media Coverage 2014. Available from: http://www.qpidhealth.com/category/media-coverage/.

34.Linder JA, Schnipper JL, Tsurikova R, Yu T, Volk LA, Melnikas AJ, Palchuk MB, Olsha-Yehiav M, Middleton B. Documentation-based clinical decision support to improve antibiotic prescribing for acute respiratory infections in primary care: a cluster randomised controlled trial. Inform Prim Care 2009; 17(4): 231-240. Epub 2010/04/03. PubMed PMID: 20359401.

35.Schnipper JL, Linder JA, Palchuk MB, Einbinder JS, Li Q, Postilnik A, Middleton B. „Smart Forms“ in an Electronic Medical Record: documentation-based clinical decision support to improve disease management. J Am Med Inform Assoc 2008; 15(4): 513-523. doi: M2501 [pii] 10.1197/jamia.M2501. PubMed PMID: 18436911; PubMed Central PMCID: PMCPMC2442258.

36. Schnipper JL, Linder JA, Palchuk MB, Yu DT, McColgan KE, Volk LA, Tsurikova R, Melnikas AJ, Einbinder JS, Middleton B. Effects of documentation-based decision support on chronic disease management. Am J Manag Care 2010; 16(12 Suppl. HIT): SP72-SP81. doi: 12789 [pii]. PubMed PMID: 21314226.

37. Horsky J, Allen MB, Wilcox AR, Pollard SE, Neri P, Pallin DJ, Rothschild, J. Analysis of user behavior in accessing electronic medical record systems in emergency departments. AMIA Annu Symp Proc 2010; 2010 : 311-315. PubMed PMID: 21346991; PubMed Central PMCID: PMCPMC3041327. 